\title{
Quality by Design Determination of Diclofenac Potassium and Its Impurities by High-Performance Liquid Chromatography
}

Anja Tumpa, Tamara Miladinović, Tijana Rakić, Ana Stajić \& Biljana JančićStojanović

To cite this article: Anja Tumpa, Tamara Miladinović, Tijana Rakić, Ana Stajić \& Biljana Jančić-Stojanović (2015): Quality by Design Determination of Diclofenac Potassium and Its Impurities by High-Performance Liquid Chromatography, Analytical Letters, DOI: 10.1080/00032719.2015.1075131

To link to this article: http://dx.doi.org/10.1080/00032719.2015.1075131

Accepted online: 06 Sep 2015.

Submit your article to this journal $₫$

Q View related articles $₫$

View Crossmark data \lceil 
Supertitle: Liquid Chromatography

\title{
Quality by Design Determination of Diclofenac Potassium and its Impurities by High-performance Liquid
}

\section{Chromatography}

\author{
Anja Tumpa \\ Department of Drug Analysis, University of Belgrade - Faculty of Pharmacy, Belgrade, Serbia \\ Tamara Miladinović \\ Pharmanova, Belgrade, Serbia \\ Tijana Rakić* \\ Department of Drug Analysis, University of Belgrade - Faculty of Pharmacy, Belgrade, Serbia \\ Ana Stajić \\ Department of Drug Analysis, University of Belgrade - Faculty of Pharmacy, Belgrade, Serbia \\ Biljana Jančić-Stojanović \\ Department of Drug Analysis, University of Belgrade - Faculty of Pharmacy, Belgrade, Serbia \\ *Address correspondence to Tijana Rakić. E-mail: tijana.rakic@ pharmacy.bg.ac.rs \\ Received 22 March 2015; accepted 14 July 2015.
}


A liquid chromatography method is reported for the determination of diclofenac potassium and its impurities using Quality by Design criteria. Central composite design was used for the investigation of the influence of critical parameters on performance that included the methanol concentration in the mobile phase, the $\mathrm{pH}$ of the aqueous phase, and the potassium dihydrogen phosphate concentration in the aqueous phase. Mathematical models enabled theoretical examination of experimental space to achieve maximal separation in minimal analysis time. A Monte Carlo simulation was used to evaluate the risk of uncertainty in model predictions, to adjusting process parameters, and to identify design space. Fractional factorial design was employed for robustness testing and method was fully validated. Optimal conditions were a C18 $150 \mathrm{~mm} \times 4.6 \mathrm{~mm}, 5 \mu \mathrm{m}$ particle size column; a methanol $-68.3 \mathrm{mmol} \mathrm{L}^{-1}$ potassium dihydrogenphosphate $(68.7: 31.3, \mathrm{v} / \mathrm{v})$ mobile phase at $\mathrm{pH} 3.0$, a flow rate of $1 \mathrm{~mL} \mathrm{~min}^{-1}$, a column temperature of $25^{\circ} \mathrm{C}$, and ultraviolet detection at $254 \mathrm{~nm}$.

Keywords: design space, diclofenac potassium, impurities, liquid chromatography, Monte Carlo simulation, quality by design

\section{INTRODUCTION}

Nowadays pharmaceutical method development can hardly be imagined without the application of Quality by Design concept. Beginning with Food and Drug Administration guidance (Food and Drug Administration's Good Manufacturing Practice for 21st Century), a new era in product development in pharmaceutical industry began. This guidance, followed by International Conference on Harmonization Q8, gave a new dimension to product development and consequently, caused many changes in product development and control. A literature survey has shown that there are many papers dealing with Quality by Design approach in method 
development (Lebrun et al. 2008; Molnár, Rieger, and Monks 2010; Debrus et al. 2011; Monks et al. 2012; Cela et al. 2013; Furlanetto et al. 2013; Kormány, Molnár, and Rieger 2013; Mbinze et al. 2013; Orlandini, Pinzauti, and Furulanetto 2013; Rozet et al. 2013; Schmidt and Molnár 2013; Hubert et al. 2014). However, despite the availability of previous studies, development of a new method demands separate attention because each mixture possesses special characteristics and requires an adjustment of investigation strategy.

Here the development and validation of a liquid chromatography (LC) method for determination of diclofenac potassium and its four impurities is presented. Structures of the analytes are presented in Figure 1. The impurities include N-chloroacetyl-N-phenyl-2, 6dichloroanilin, 1-(2, 6-dichlophenyl)-2-indolinon, N-phenyl-2,6-dichloranilin, and 2-indolinon (1-H-indol-2-ol).

Many reports have described LC methods for the determination of diclofenac sodium or diclofenac potassium and other drugs in pharmaceutical formulations (Ye and Zhang 2000; Krzek and Starek 2002; Bisas and Basu 2010; Elkady 2010; Gowramma et al. 2010; Khatal et al. 2010; Rele et al. 2011; Ambekar, Choudhari, and Ingale 2012; Chaple et al. 2012; Panda, Patanaik, and Ravi Kumar 2012; Rubim et al. 2013; Shaalan and Belal 2013; Belal et al. 2014; Rubim et al. 2014). Here these impurities were investigated together for the first time. Previous papers have considered 1-(2, 6-dichlophenyl)-2-indolinon and 2-indolinon (Krzek and Starek 2002), while others examined N-chloroacetyl-N-phenyl-2, 6-dichloroanilin and N-phenyl-2, 6dichloranilin (Shaalan and Belal 2013; Belal et al. 2014). The Quality by Design approach with Monte Carlo simulations allows development of better methods than those without the implementation of these approaches. In addition, high-performance thin layer chromatography was used for the determination of diclofenac potassium (Ali et al. 2012; Mohite, Potawale, and 
Gabhe 2013). Also, methods were reported for diclofenac sodium and diclofenac potassium determination in biological samples (Lee et al. 2000; Su et al. 2006; BhanuPraksah, VijayaSri, and Rama Krishna 2009; Sarfraz, Sarfraz, and Ahmad 2011; Prasad et al. 2012; Sahoo et al. 2015). A method for diclofenac potassium is available in the European Pharmacopoeia Seventh Edition using isocratic conditions with an analysis time of 40 minutes for the determination of diclofenac potassium and its impurities. N-Chloroacetyl-N-phenyl-2,6 dichloroanilin and $\mathrm{N}$ phenyl-2,6-dichloranilin are not presented in the Seventh Edition European Pharmacopoeia, although 1-(2, 6-dichlophenyl)-2-indolinon and 2-indolinon(1-H-indol-2-ol) are included. The goal of this study was to develop a liquid chromatography method for the determination of diclofenac potassium and these four impurities using Quality by Design principles. This is the first report involving N-chloroacetyl-N-phenyl-2, 6 dichloroanilin and N-phenyl-2, 6dichloranilin with diclofenac potassium and two other impurities. This approach allowed the development of reliable and reproductive chromatographic conditions.

\section{EXPERIMENTAL}

\section{Chemicals and Reagents}

The analytes diclofenac potassium and the impurities (Dipharma Francis s.r.l., Italy) were of analytical grade. The mobile phase and the solvents were prepared from methanol (J. T. Baker, Neatherlands), potassium dihydrogen phosphate (Sigma; Aldrich, Germany), o phosphoric acid (Carlo Erba, Italy), and liquid chromatography grade water. Diclofenac potassium tablets were obtained from the local markets.

\section{Chromatographic Conditions}


The chromatographic system Waters Breeze included a Waters 1525 Binary HPLC Pump, Waters 2487 ultraviolet visible spectroscopy dual absorbance detector, and Breeze Software. Separations were performed on the Zorbax Extend XDB-C18 $150 \mathrm{~mm} \times 4.6 \mathrm{~mm}$, $5 \mu \mathrm{m}$ particle size column (Agilent Technologies, St. Clara, USA). The samples were introduced through a Rheodyne injector valve with a $20 \mu \mathrm{L}$ sample loop. The flow rate of the mobile phase was $1 \mathrm{~mL} \min ^{-1}$ at $25^{\circ} \mathrm{C}$ with ultraviolet detection at $254 \mathrm{~nm}$. A mixture of methanol-water (70:30 v/v) was employed as the solvent.

\section{Mobile Phase}

The mobile phase consisted of methanol with aqueous potassium dihydrogsen phosphate. The mobile phase $\mathrm{pH}$ was adjusted with phosphoric acid. The amount of organic solvent, the concentration of potassium dihydrogen phosphate in the aqueous phase, and the $\mathrm{pH}$ of the mobile phase were varied according the experimental design procedure. The mobile phase for the optimal chromatographic conditions included methanol and $68.3 \mathrm{mmol} \mathrm{\textrm {L } ^ { - 1 }}$ potassium dihydrogenphosphate in water at 68.7:31.3(v/v) at $\mathrm{pH} 3.0$.

\section{Optimization and Robustness}

The stock solution was prepared by dissolving diclofenac potassium and the impurities in methanol. The concentration of diclofenac potassium was $1 \mathrm{mg} \mathrm{mL}-1$ and of impurities were $200 \mu \mathrm{g} \mathrm{mL} \mathrm{m}^{-1}$. In order to obtain working standards, the stock solutions were diluted to $100 \mu \mathrm{g}$ $\mathrm{mL}^{-1}$ for diclofenac potassium and $10 \mu \mathrm{g} \mathrm{mL} \mathrm{m}^{-1}$ for the impurities with solvent.

\section{Selectivity}


In order to evaluate the selectivity of the LC method, a placebo mixture was prepared in a ratio corresponding to the concentration in the tablets. A standard solution, containing $100 \mu \mathrm{g}$ $\mathrm{mL}^{-1}$ of diclofenac potassium and $2 \mu \mathrm{g} \mathrm{mL} \mathrm{m}^{-1}$ of each impurity, was utilized to characterize the selectivity.

\section{Stock Solutions}

Stock solutions were prepared by dissolving diclofenac potassium and its impurities in methanol to obtain $1 \mathrm{mg} \mathrm{mL}^{-1}$ for diclofenac potassium and $100 \mu \mathrm{g} \mathrm{mL}{ }^{-1}$ for the impurities.

\section{Evaluation of the Linear Dynamic Range}

For the construction of the calibration curve, eight solutions containing diclofenac potassium from $25 \mu \mathrm{g} \mathrm{mL} \mathrm{m}^{-1}$ to $250 \mu \mathrm{g} \mathrm{mL}^{-1}$ were prepared. For impurities, the linearity was evaluated using seven solutions across the following concentrations: N-chloroacetyl-N-phenyl-2, 6-dichloroanilin from $0.5 \mu \mathrm{g} \mathrm{mL} \mathrm{m}^{-1}$ to $15 \mu \mathrm{g} \mathrm{mL} \mathrm{m}^{-1}$, 1-(2, 6-dichlophenyl)-2-indolinon from $0.15 \mu \mathrm{g} \mathrm{mL}^{-1}$ to $10 \mu \mathrm{g} \mathrm{mL}{ }^{-1}$, for $\mathrm{N}$-phenyl-2, 6-dichloranilin from $0.5 \mu \mathrm{g} \mathrm{mL}^{-1}$ to $6 \mu \mathrm{g} \mathrm{mL} \mathrm{m}^{-1}$, and for 2-indolinon (1-H-indol-2-ol) from $0.15 \mu \mathrm{g} \mathrm{mL}{ }^{-1}$ to $5 \mu \mathrm{g} \mathrm{mL}^{-1}$.

\section{Evaluation of Accuracy}

A solution containing placebo, diclofenac potassium, and its impurities were prepared in methanol and sonicated for 10 minutes. This solution was then used for the preparation of solutions at $80 \%, 100 \%$ and $120 \%$ levels.

\section{Evaluation of Precision}


The precision was determined using diclofenac potassium pharmaceutical products containing $50 \mathrm{mg}$ of active substance per tablet. The concentrations of impurities were below the limit of detection, so the sample was fortified. A tablet mass containing $25 \mathrm{mg}$ of diclofenac potassium was fortified with impurities; solvent was added and the solution was sonicated for 15 minutes. The solution was filtered to obtain $1 \mathrm{mg} \mathrm{mL}-1$ and $20 \mu \mathrm{g} \mathrm{mL} L^{-1}$ for diclofenac potassium and the impurities, respectively. This solution was diluted to provide $200 \mu \mathrm{g} \mathrm{mL} \mathrm{L}^{-1}$ and $4 \mu \mathrm{g} \mathrm{mL} \mathrm{L}^{-1}$ for diclofenac potassium and impurities. This procedure was repeated six times.

\section{Analysis of Tablets}

A pulverised tablet mass containing $25 \mathrm{mg}$ of diclofenac potassium was extracted with $25 \mathrm{~mL}$ solvent in an ultrasonic bath during $15 \mathrm{~min}$ and filtered. This stock solution was used to prepare six solutions containing $200 \mu \mathrm{g} \mathrm{mL} L^{-1}$ of diclofenac potassium.

\section{Software}

The experiments for optimization and robustness testing, as well method optimization and Design Space definitions were performed in Modde 10.1 (Umetrics, Umea, Sweden).

\section{RESULTS AND DISCUSSION}

Quality by Design is well-defined in International Conference on Harmonization Q8 and is largely complete in the International Conferences on Harmonization Q9 and Q10. General characteristics of this approach mean that risk management, scientific knowledge, and improved process understanding lead to more efficient and robust response in defined design space. Hence, an analytical method was developed that fulfills the criteria defined with this approach. Regardless of whether drug is generic or newly synthesized, this approach should be 
incorporated in method development. Here an LC method was developed for diclofenac potassium and its impurities in line with Quality by Design principles.

\section{Analytical Target Profile and Critical Quality Attributes}

Quality by Design method development starts with definition of analytical target profile which is a set of criteria that defines what is measured and the required performance criteria of the method denoted as critical quality attributes (Orlandini, Pinzauti, and Furulanetto 2013; Rozet et al. 2013). In order to define critical quality attributes, preliminary studies were conducted. Taking into account the nature of investigated substances, a $\mathrm{C}_{18}$ column was chosen as stationary phase. Some chromatographic factors were set at defined levels at the beginning of the study, while other factors such as the organic modifier, aqueous phase composition, and $\mathrm{pH}$ of the mobile phase were varied. This study has shown that the elution order, 2-indolinon $(1-\mathrm{H}-$ indol-2-ol) before 1-(2, 6-dichlophenyl)-2-indolinon before N-chloroacetyl-N-phenyl-2, 6dichloroanilin before diclofenac potassium before N-phenyl-2, 6-dichloranilin, was not affected by these changes. Also, methanol concentrations less than $60 \%$ caused long run times while values higher than $70 \%$ influenced the quality of the separation. Consequently, the methanol concentration was varied from $60 \%$ to $70 \%$. Buffer concentrations from $25 \mathrm{mM}$ to $75 \mathrm{mM}$ were employed to evaluate the influence on the separation because small variations did not significantly affect the separation. Considering properties of investigated substances, $\mathrm{pH}$ values from 2.5 to 3.5 were selected for further investigation.

The main objective of the study was the development of a method for the determination of diclofenac potassium and four impurities with maximal separation and minimal analysis time. Therefore, the selectivity factor of the critical peak pair, diclofenac potassium and N-phenyl-2, 6- 
dichloranilin, was defined as a critical quality attribute and the goal was to maximize its value. The analysis time was characterized as the retention factor of the last eluting peak as the retention factor for N-phenyl-2, 6-dichloranilin. Hence this parameter was the second critical quality attribute and the goal was to minimize this response. Finally, apart from achieving satisfactory values of defined critical quality attributes, the optimal point should be surrounded with sufficient design space. In this case, the methanol concentration in the mobile phase, the concentration of buffer in mobile phase, and the $\mathrm{pH}$ of the mobile phase were defined as critical process parameters and were further investigated.

\section{Knowledge Space and Critical Quality Attribute Modeling}

Critical quality attributes modeling is one of the key steps in Quality by Design development and definition of design space. The establishment of mathematical relationships between process parameters and important responses allows simulation of chromatographic processes and many theoretical experiments without the necessity for real experiments. During preliminary experiments, factors and their levels were defined. For deep understanding and investigating the influence of those selected factors on important responses, face centered central composite design was selected (Massart et al. 1997). The experimental plan defined by the applied design is presented in Table $\mathbf{1}$.

Experiments were performed randomly and the retention factor for N-phenyl-2, 6dichloranilin and the selectivity factor for diclofenac potassium and N-phenyl-2,6-dichloranilin were monitored as critical quality attributes. Multiple linear regression and least squares methods were applied for creation of mathematical models. The best models for responses were investigated. The values of coefficient of determination, adjusted coefficient of determination, 
and predicted coefficient of determination were applied as indicators of model quality. Optimization of the values was done by removal of insignificant model terms. High values of coefficient of determination (higher than 0.776) and adjusted coefficient of determination (higher than 0.776$)$ suggested that the models adequately fitted the investigated responses. In order to visualize the dependence of selected optimization, critical quality attributes on contour plots were constructed and presented in Figure 2.

\section{Design Space and Working Point}

Design space is the most important component of Quality by Design concept and its definition is a key part of method development. Design space provides definition of edges of failure, outside of which the method performances are not acceptable (Orlandini, Pinzauti, and Furulanetto 2013). These edges are defined graphically or by appropriate mathematical equations and ensure that the theoretical robustness is acquired within marked region. The method operating conditions are not defined as discrete points, but as a working space which decreases the chances for method failure (Mbinze et al. 2012).

The threshold of acceptable values for the selectivity factor of diclofenac potassium and $\mathrm{N}$-phenyl-2, 6-dichloranilin was 1.12; for the retention factor of N-phenyl-2, 6-dichloranilin, a value of 10 was selected. Sweet spot regions were constructed by overlay of contour plots for analyzed responses and are presented in Figure 3. The green area shows where both critical quality attributes defined criteria are met, while blue region shows where only one of the criteria

is met. The large green area provides the surface where the changes of critical process parameters do not give variation in critical quality attributes. However, this region does consider possible variation in precision of the investigated critical process parameters and model error. 
Therefore, design space was created applying Monte Carlo simulations and mathematical models. This approach allows calculation of the risk of obtaining undesired results for each point in knowledge space.

Once the design space was established, each point within it may be a possible working point. It can be selected as point with highest separation quality, or on the basis of practical considerations. Also, the optimal point may be selected with the highest probability that critical quality attributes are within specifications, i.e., as the most robust point. Here, the most robust set point was identified. Therefore, the robust optimization was performed and the working point was selected as the one surrounded with the greatest design space. The optimum was at a methanol concentration of $68.7 \%$ in the mobile phase, a $\mathrm{pH}$ value 3.0 , and potassium dihydrogen phosphate at $68.3 \mathrm{mmol} \mathrm{L}^{-1}$. The resulting design space is presented in Figure 4.

The obtained borders of design space present the region where the changes of critical process parameters do not disturb the quality of the method with a probability of $90 \%$. The identified critical process parameters ranges were: $65.3 \%$ to $72.0 \%$ for methanol concentration in the mobile phase, 29.83 to $106.83 \mathrm{mmol} \mathrm{L}^{-1}$ potassium dihydrogen phosphate in the aqueous phase, and $\mathrm{pH}$ from 2.5 to 3.5 . However, the upper limits for potassium dihydrogen phosphate concentration were outside the investigated knowledge space. Therefore, they were corrected to the upper border of the knowledge space: $75 \mathrm{mmol} \mathrm{L}^{-1}$ for potassium dihydrogen phosphate. The optimal conditions were verified experimentally as shown in Figure 5.

\section{Robustness}

Although design space presents the region of theoretical robustness, robustness testing is required for method validation. Therefore, design of experiments methodology was used to 
explore robustness close to the optimal point. The factors monitored in this phase were the three critical process parameters identified in optimization phase and two additional factors: column temperature and mobile phase flow rate. The ranges of factor variation were selected to be symmetrical around the nominal value. For evaluation of these five factors on robustness, fractional factorial design was chosen using $1 / 4$ fraction of full factorial design. The experimental plan was set according to fractional factorial design $2^{5-3}$ and is presented in Table 2. In addition to these experiments, three measurements were performed at the central point. The same responses as in the optimization phase were followed. The experiments are performed randomly and the results are presented in Table 2.

The results were evaluated and coefficients for the primary effects are shown in Table 3. Statistical evaluation of results obtained from robustness testing was done by the algorithm of

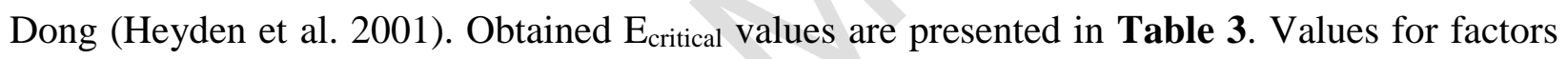
effects for both responses are above the calculated $E_{\text {critical, }}$ showing the insignificance of all factors in robustness testing.

\section{Validation}

The next step was to perform method validation. Under the optimal conditions, a placebo mixture, standards, and a solution for precision estimation were analyzed. There were no interferences, confirming the selectivity of the method. The linear dynamic range, accuracy, precision, and limits of detection (LOD) and quantification (LOQ) for the analytes were

determined and obtained results are shown in Table 4. The results for all measurements were within the required values (Crowther 2001). 
The method was employed for the analysis of tablets containing $50 \mathrm{mg}$ of diclofenac potassium. The impurities were below the limit of quantification and the determined concentration of diclofenac potassium was $99.8 \%$ (49.9 $\mathrm{mg}$ per tablet).

\section{CONCLUSIONS}

A liquid chromatography method is reported for diclofenac potassium and four impurities in accordance with Quality by Design. The importance of this strategy in modern pharmaceutical analysis is emphasized and each step of the process is described in detail. Special attention was devoted to design of experiments for creation of reliable mathematical models. The study provided optimal chromatographic conditions for diclofenac potassium and its impurities in a well-defined, robust region. The method was validated and used for the analysis of real samples to verify the applicability of the method.

\section{Acknowledgment}

The authors thank the Ministry of Education, Science and Technological Development of the Republic of Serbia for supporting these investigations in Project 172052.

\section{References}

Ali, N., M. Hegazy, M. Abdelkawy, and E. Abdelaleem. 2012. Simultaneous determination of methocarbamol and its related substance (Guaifenesin) in two ternary mixtures with ibuprofen and diclofenac potassium by HPTLC spectrodensitometric method. Journal of Planar Chromatography - Modern TLC 25:150-55. doi:10.1556/jpc.25.2012.2.11

Ambekar, A. M., V. Choudhari, and K. Ingale. 2012. Development and validation of a stabilityindicating LC method for simultaneous analysis of drotaverine hydrochloride and diclofenac potassium and its application for formulation analysis. International Journal of Pharmaceutical Sciences Review and Research 12:132-36.

Belal, T. S., M. M. Bedair, A. A. Gazy, and K. M. Guirguis. 2014. Validated Selective HPLCDAD method for the simultaneous determination of diclofenac sodium and lidocaine 
hydrochloride in presence of four of their related substances and potential impurities. Acta Chromatographica 27:477-93. doi:10.1556/AChrom.27.2015.3.6

BhanuPraksah, T., K. VijayaSri, and S. Rama Krishna. 2009. Determination of diclofenac potassium in human plasma by LC-MS. Asian Journal of Organic Chemistry 21:418389.

Bisas, A., and A. Basu. 2010. Simultaneous estimation of paracetamol, chlorzoxazone and diclofenac potassium in pharmaceutical formulation by a RP HPLC method. International Journal of Pharmaceutical Research and Bio-Science 1:127.

Cela, R., E. Y. Ordonez, J. B. Quintana, and R. Rodil. 2013. Chemometric-assisted method development in reversed-phase liquid chromatography. Journal of Chromatography A 1287:2-22. doi:10.1016/j.chroma.2012.07.081

Chaple, D. R., S. A. Mehta, M. P. Yeole, and P. S. Tarte. 2012. Development of stability indicating analytical method for famotidine and diclofenac potassium in combined dosage form. Indian Drugs 49:40-42.

Crowther, J. B. 2001. Validation of pharmaceutical test methods. In Handbook of modern pharmaceutical analysis, ed. S. Ahuja and S. Scypinski, vol. 3, 1st ed., 415-43. New York: Academic Press.

Dahivelkar, P. P., S. I. Bhoir, S. B. Bari, S. J. Surana, and A. M. Bhagwat. 2012. Simultaneous determination of diclofenac potassium and drotaverine hydrochloride in human plasma using reversed-phase high performance liquid chromatography. Journal of Chromatographic Science 50:694-701. doi:10.1093/chromsci/bms026

Debrus, B., P. Lebrun, J. M. Kindenge, F. Lecomte, A. Ceccato, G. Caliaro, J. M. T. Mbay, B. Boulanger, R. D. Marini, E. Rozet, and P. Hubert. 2011. Innovative high-performance liquid chromatography method development for the screening of 19 antimalarial drugs based on a generic approach, using design of experiments, independent component analysis and design space. Journal of Chromatography A 1218:5205-15. doi:10.1016/j.chroma.2011.05.102

Elkady, E. F. 2010. Simultaneous determination of diclofenac potassium and methocarbamol in ternary mixture with guaifenesin by reversed phase liquid chromatography. Talanta 82:1604-07. doi:10.1016/j.talanta.2010.07.024

Furlanetto, S., S. Orlandini, B. Pasquini, M. Del Bubba, and S. Pinzauti.2013Quality by Design approach in the development of a solvent-modified micellar electrokinetic chromatography method: Finding the design space for the determination of amitriptyline and its impurities. Analytica Chimica Acta 802:113-24. doi:10.1016/j.aca.2013.10.005

Gowramma, B., S. Rajan, S. Muralidharan, S. N. Meyyanathan, and B. Suresh. 2010. A validated RP-HPLC method for simultaneous estimation of paracetamol and diclofenac potassium in pharmaceutical formulation. International Journal of ChemTech Research 2:676-80.

Heyden, H. V., A. Nijhuis, J. Smeyers-Verbeke, B. G. M. Vandeginste, and D. L. Massart. 2001. Guidance for robustness/ruggedness tests in method validation. Journal of Pharmaceutical and Biomedical Analysis 24:723-53. doi:10.1016/s0731-7085(00)00529$\mathrm{X}$

Hubert, C., P. Lebrun, S. Houari, E. Ziemons, E. Rozet, and P. Hubert. 2014. Improvement of a stability-indicating method by Quality-by-Design versus Quality-by-Testing: A case of a learning process. Journal of Pharmaceutical and Biomedical Analysis 88:401-09. doi:10.1016/j.jpba.2013.09.026 
Khatal, L. D., A. Y. Kamble, M. V. Mahadik, and S. R. Dhaneshwar. 2010. Validated HPTLC method for simultaneous quantitation of paracetamol, diclofenac potassium, and famotidine in tablet formulation. Journal of AOAC International 93:765-70.

Kormány, R., I. Molnár, and H.-J. Rieger. 2013. Exploring better column selectivity choices in ultra-high performance liquid chromatography using quality by design principles. Journal of Pharmaceutical and Biomedical Analysis 80:79-88. doi:10.1016/j.jpba.2013.02.028

Krzek, J., and M. Starek. 2002. Densitometric determination of diclofenac, 1-(2,6dichlorophenyl)indolin-2-one and indolin-2-one in pharmaceutical preparations and model solutions. Journal of Pharmaceutical and Biomedical Analysis 28:227-43. doi:10.1016/s0731-7085(01)00622-7

Lebrun, P., B. Govaerts, B. Debrus, A. Ceccato, G.Caliaro, P. Hubert, and B. Boulanger, 2008. Development of a new predictive modelling technique to find with confidence equivalence zone and design space of chromatographic analytical methods. Chemometrics and Intelligent Laboratory Systems 9:4-16. doi:10.1016/j.chemolab.2007.05.010

Lee, H. S., C. K. Jeong, S. J. Choi, S. B. Kim, M. H. Lee, G. I. Ko, and D. H. Sohn. 2000. Simultaneous determination of aceclofenac and diclofenac in human plasma by narrow bore HPLC using column-switching. Journal of Pharmaceutical and Biomedical Analysis 23:775-81. doi:10.1016/s0731-7085(00)00381-2

Massart, D. L., B. G. M. Vandeginste, L. M. C. Buydens, S. De Jong, P. J. Lewi, and J. SmeyersVerbeke. 1997. Handbook of chemometrics and qualimetrics: Part A. In Handling in science and technology, vol. 20A, 1st ed. Amsterdam: Elsevier.

Mbinze, J. K., A. Dispas, P. Lebrun, J. M. Mbay, V. Habyalimana, N. Kalenda, E. Rozet, P. Hubert, and R. D. Marini. 2013. Application of an innovative design space optimization strategy to the development of LC methods for the simultaneous screening of antibiotics to combat poor quality medicines. Journal of Pharmaceutical and Biomedical Analysis 85:83-92. doi:10.1016/j.jpba.2013.06.036

Mbinze, J. K., P. Lebrun, B. Debrus, A. Dispas, N. Kalenda, J. M. Mbay, T. Schofield, B. Boulanger, E. Rozet, P. Hubert, and R. D. Marini. 2012. Application of an innovative design space optimization strategy to the development of liquid chromatographic methods to combat potentially counterfeit nonsteroidal anti-inflammatory drugs. Journal of Chromatography A 1263:113-24. doi:10.1016/j.chroma.2012.09.038

Mohite, V. I., S. E. Potawale, and S. Y. Gabhe. 2013. Development and validation of HPTLC method for simultaneous estimation of paracetamol, diclofenac potassium and chlorzoxazone in bulk drug and tablet dosage form. International Journal of Pharmacy and Pharmaceutical Sciences 5:432-35.

Molnár, I., H. J. Rieger, and K. E. Monks. 2010. Aspects of the "Design Space" in high pressure liquid chromatography method development. Journal of Chromatography A 1217:3193200. doi:10.1016/j.chroma.2010.02.001

Monks, K., I. Molnár, H. J. Rieger, B. Bogáti, and E. Szabó. 2012. Quality by Design: Multidimensional exploration of the design space in high performance liquid chromatography method development for better robustness before validation. Journal of Chromatography A 1232:218-30. doi:10.1016/j.chroma.2011.12.041

Orlandini, S., S. Pinzauti, and S. Furulanetto. 2013. Application of quality by design to the development of analytical separation methods. Analytical and Bioanalytical Chemistry 405:443-50. doi:10.1007/s00216-012-6302-2 
Panda, S. S., D. Patanaik, and B. V. V. Ravi Kumar. 2012. New stability-indicating RP-HPLC method for determination of diclofenac potassium and metaxalone from their combined dosage form. Scientia Pharmaceutica 80:127-37. doi:10.3797/scipharm.1109-16

Rele, R. V., J. M. Parab, V. V. Mhatre, and C. B. Warkar. 2011. Simultaneous RP-HPLC determination of diclofenac potassium and famotidine in pharmaceutical preparations. Research Journal of Pharmacy and Technology 4:638-41.

Rozet, E., P. Lebrun, B. Debrus, P. Boulanger, and P. Hubert. 2013. Design Space for analytical methods. TrAC - Trends in Analytical Chemistry 42:157-67.

Rubim, A. M., J. B. Rubenick, L. V. Laporta, and C. M. B. Rolim. 2013. A simple method for the quantification of diclofenac potassium in oral suspension by high-performance liquid chromatography with UV-detection. Brazilian Journal of Pharmaceutical Sciences 49:589-97. doi:10.1590/s1984-82502013000300021

Rubim, A. M., J. B., Rubenick, L. V. Laporta, and C. M. B. Rolim. 2014. Development and validation of a dissolution method using HPLC for diclofenac potassium in oral suspension. Brazilian Journal of Pharmaceutical Sciences 50:423-29. doi:10.1590/s1984-82502014000200022

Sahoo, N. K., M. Sahu, P. S. Rao, and G. Ghosh. 2015. Solid phase extraction and quantification of diclofenac sodium in human plasma by liquid chromatography-tandem mass spectrometry. Journal of Analytical Chemistry 70:424-30. doi: $10.1134 / \mathrm{s} 1061934815040115$

Sarfraz, A., M. Sarfraz, and M. Ahmad. 2011. Development and validation of a bioanalytical method for direct extraction of diclofenac potassium from spiked plasma. Tropical Journal of Pharmaceutical Research 10:663-69. doi:10.4314/tjpr.v10i5.16

Schmidt, A. H., and I. Molnár. 2013. Using an innovative Quality-by-Design approach for development of a stability indicating UHPLC method for ebastine in the API and pharmaceutical formulations. Journal of Pharmaceutical and Biomedical Analysis 7879:65-74. doi:10.1016/j.jpba.2013.01.032

Shaalan, R. A., and T. S. Belal. 2013. Validated stability-indicating HPLC-DAD method for the simultaneous determination of diclofenac sodium and diflunisal in their combined dosage form. Scientia Pharmaceutica 81:713-31. doi:10.3797/scipharm.1301-24

Su, J. Y., D. H. Yu, Y. Li, and D. W. Chen. 2006. Study on pharmacokinetics and bioequivalence of diclofenac potassium sustained-release tablets in dogs. Chinese Pharmaceutical Journal 41:1576-79.

US Food and Drug Administration (FDA). 2007. Department of health and human services, pharmaceutical quality for 21st century, a risk based approach progress report. http://www.fda.gov/AboutFDA/CentersOffices/CDER/ucm128080.html.

2005. ICH of Technical Requirements for Registration of Pharmaceuticals for Human Use, Topic Q9: Quality Risk Management, Geneva.

2008. ICH of Technical Requirements for Registration of Pharmaceuticals for Human Use, Topic Q10: Pharmaceutical quality System, Geneva.

2009. ICH of Technical Requirements for Registration of Pharmaceuticals for Human Use, Topic Q8 (R2): Pharmaceutical Development, Geneva.

2011. European pharmacopoeia, 7th ed. Strasbourg: Council of Europe.

Ye, H., and M. Zhang. 2000. RP-HPLC simultaneously determination of diclofenac sodium, misoprostol and its related impurities in compound misoprostol tablet. Chinese Pharmaceutical Journal 35:192-94. 
Table 1. Face centered central composite design, retention factor for N-phenyl-2, 6dichloranilin, and selectivity factor for diclofenac potassium and N-phenyl-2, 6-dichloranilin

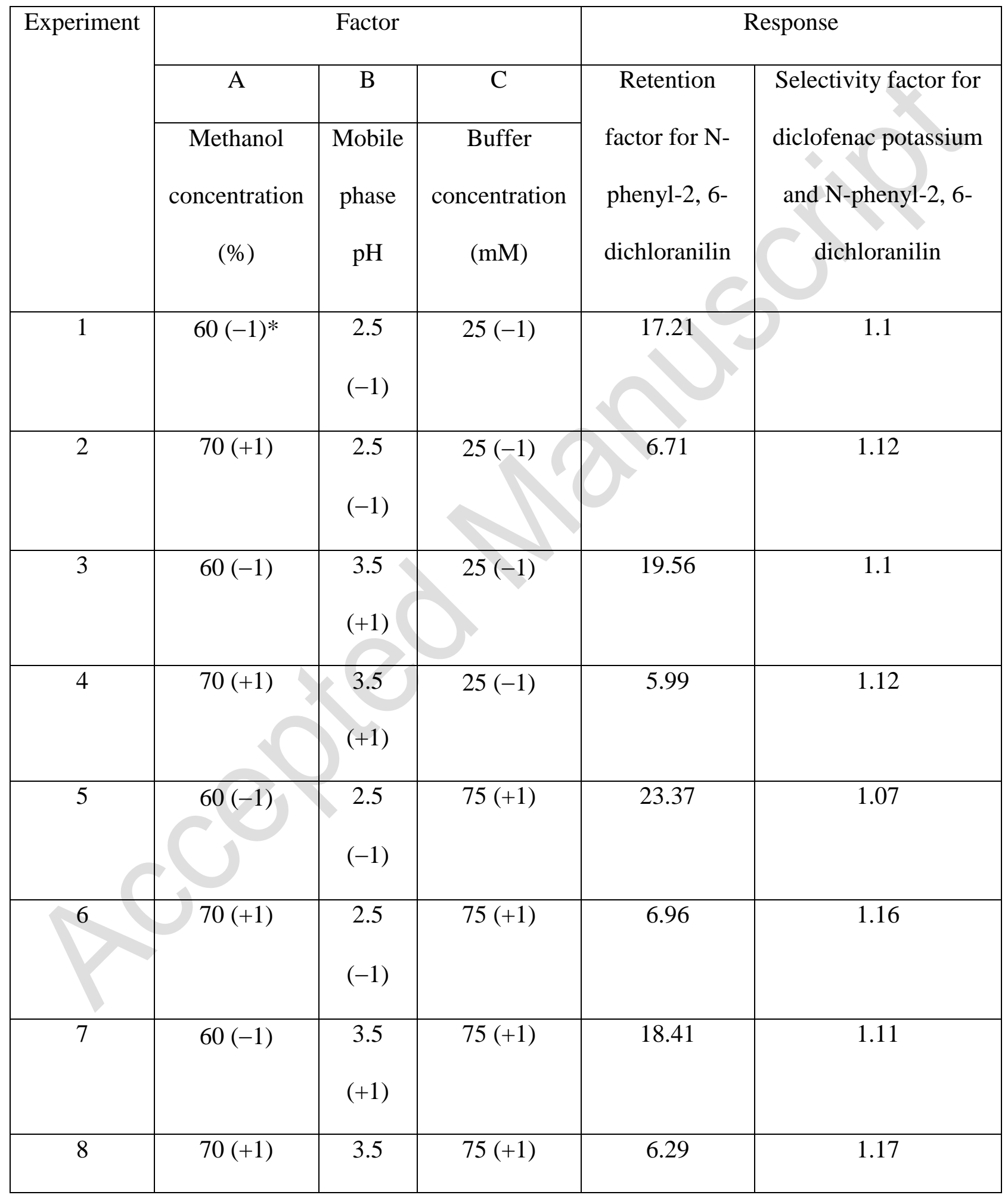




\begin{tabular}{|c|c|c|c|c|c|}
\hline & & $(+1)$ & & & \\
\hline 9 & $60(-1)$ & $3.0(0)$ & $50(0)$ & 23.22 & 1.07 \\
\hline 10 & $70(+1)$ & $3.0(0)$ & $50(0)$ & 7.03 & 1.17 \\
\hline 11 & $65(0)$ & $\begin{array}{l}2.5 \\
(-1)\end{array}$ & $50(0)$ & 12.5 & 1.14 \\
\hline 12 & $65(0)$ & $\begin{array}{l}3.5 \\
(+1)\end{array}$ & $50(0)$ & 10.4 & \\
\hline 13 & $65(0)$ & $3.0(0)$ & $25(-1)$ & 11.92 & 1.12 \\
\hline 14 & $65(0)$ & $3.0(0)$ & $75(+1)$ & 11.79 & 1.13 \\
\hline 15 & $65(0)$ & $3.0(0)$ & $50(0)$ & 11.95 & 1.14 \\
\hline 16 & $65(0)$ & $3.0(0)$ & $50(0)$ & 11.82 & 1.13 \\
\hline 17 & $65(0)$ & $3.0(0)$ & $50(0)$ & 10.94 & 1.12 \\
\hline
\end{tabular}

*Coded values are in parentheses. 
Table 2. Robustness characterized by fractional factorial design $2^{5-2}$, retention factor for Nphenyl-2, 6-dichloranilin, and selectivity factor for diclofenac potassium and N-phenyl-2, 6dichloranilin

\begin{tabular}{|c|c|c|c|c|c|c|c|}
\hline $\begin{array}{c}\text { Experime } \\
\mathrm{nt}\end{array}$ & $\begin{array}{c}\text { Methanol } \\
\text { concentrati } \\
\text { on }(\%)\end{array}$ & $\begin{array}{c}\text { Buffer } \\
\text { concentrati } \\
\text { on }(\mathrm{mM})\end{array}$ & $\begin{array}{c}\text { Mobil } \\
\mathrm{e} \\
\text { phase } \\
\mathrm{pH}\end{array}$ & $\begin{array}{l}\text { Column } \\
\text { temperatur } \\
\text { e }\left({ }^{\circ} \mathrm{C}\right)\end{array}$ & $\begin{array}{c}\text { Flow } \\
\text { rate } \\
(\mathrm{mL} \\
\mathrm{min}^{-1} \\
)\end{array}$ & $\begin{array}{l}\text { Retention } \\
\text { factor for } \\
\text { N-phenyl- } \\
2,6- \\
\text { dichloranili } \\
\text { n }\end{array}$ & $\begin{array}{l}\text { Selectivity } \\
\text { factor for } \\
\text { diclofenac } \\
\text { potassium } \\
\text { and N- } \\
\text { phenyl-2, } \\
\text { 6- } \\
\text { dichloranili } \\
n\end{array}$ \\
\hline 1 & 66.7 & 63.3 & 2.8 & 27 & 1.1 & 5.886 & 1.177 \\
\hline 2 & 70.7 & 63.3 & 2.8 & 23 & 0,9 & 7.565 & 1.18 \\
\hline 3 & 66.7 & 73.3 & 2.8 & 27 & 1.1 & 6.517 & 1.146 \\
\hline 4 & 70.7 & 73.3 & 2.8 & 23 & 0.9 & 6.429 & 1.179 \\
\hline 5 & 66.7 & 63.3 & 3.2 & 27 & 1.1 & 9.728 & 1.161 \\
\hline 6 & 70.7 & 63.3 & 3.2 & 23 & 0.9 & 6.104 & 1.142 \\
\hline 7 & 66.7 & 73.3 & 3.2 & 27 & 1.1 & 11.672 & 1.17 \\
\hline 8 & 70.7 & 73.3 & 3.2 & 23 & 0.9 & 5.23 & 1.186 \\
\hline 9 & 68.7 & 68.3 & 3.0 & 25 & 1.0 & 7.272 & 1.151 \\
\hline 10 & 68.7 & 68.3 & 3.0 & 25 & 1.0 & 6.997 & 1.155 \\
\hline 11 & 68.7 & 68.3 & 3.0 & 25 & 1.0 & 7.022 & 1.157 \\
\hline
\end{tabular}


Table 3. Coefficients from the mathematical models for robustness and their statistical significance

\begin{tabular}{|c|c|c|}
\hline \multirow[t]{2}{*}{ Coefficient } & \multicolumn{2}{|c|}{ Response } \\
\hline & $\begin{array}{l}\text { Retention factor for } \mathrm{N}- \\
\text { phenyl-2, 6-dichloranilin }\end{array}$ & $\begin{array}{l}\text { Selectivity factor for diclofenac } \\
\text { potassium and N-phenyl-2, 6- } \\
\text { dichloranilin }\end{array}$ \\
\hline Constant & 3.9463 & 76.9865 \\
\hline Methanol content $(\%)$ & -0.57177 & 0.2728 \\
\hline $\begin{array}{l}\text { Buffer concentration } \\
\qquad(\mathrm{mM})\end{array}$ & 0.03806 & 0.1736 \\
\hline $\mathrm{pH}$ of the mobile phase & 0.4274 & -0.1901 \\
\hline $\begin{array}{c}\text { Column temperature } \\
\left({ }^{\circ} \mathrm{C}\right)\end{array}$ & -0.3092 & 0.5374 \\
\hline Flow rate $\left(\mathrm{mL} \mathrm{min}{ }^{-1}\right)$ & -0.7865 & -0.3224 \\
\hline $\begin{array}{c}\text { Ecritical calculated } \\
\text { according to Heyden et } \\
\text { al. (2001) }\end{array}$ & 1.2727 & 0.7790 \\
\hline
\end{tabular}


Table 4. Analytical figures of merit

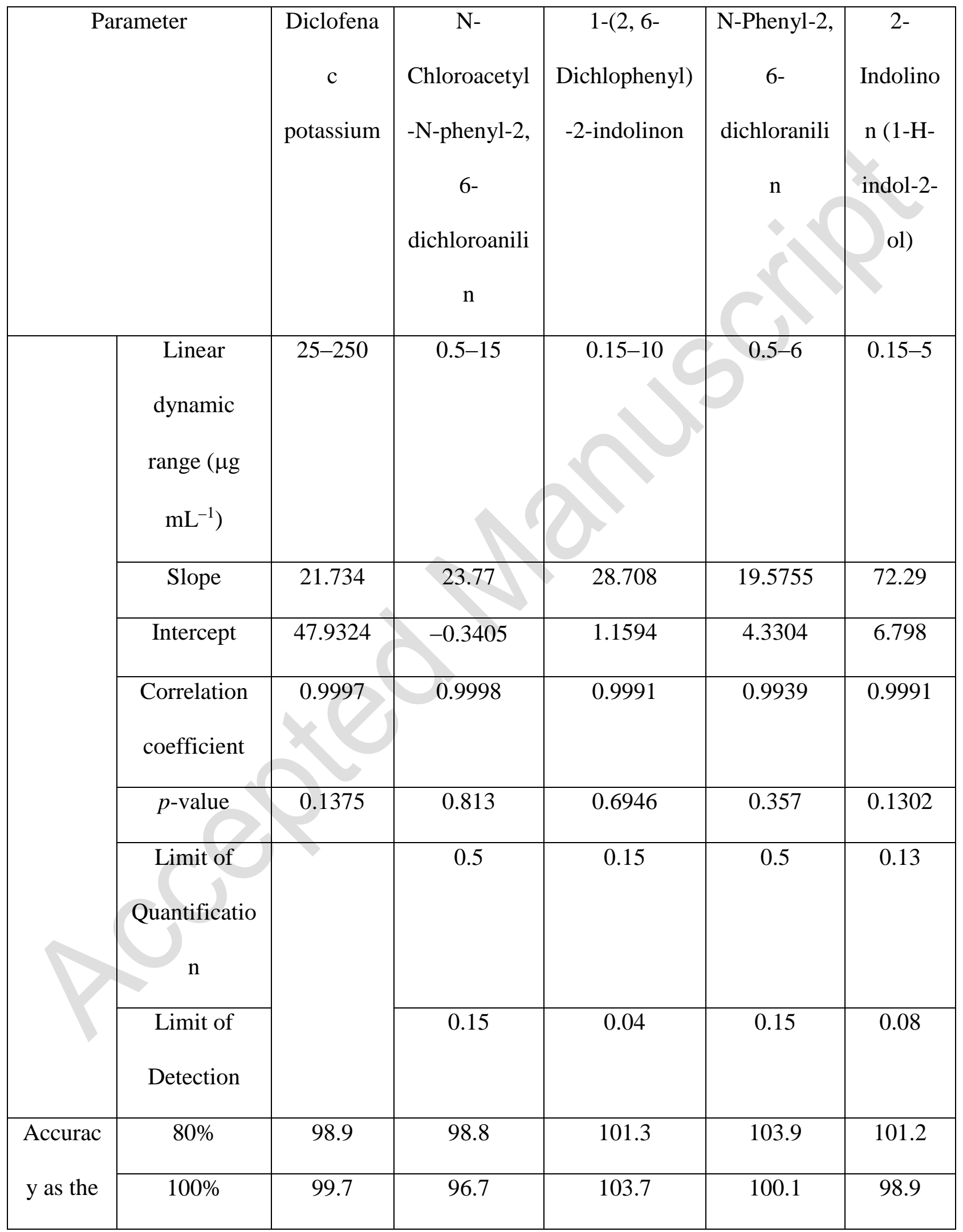




\begin{tabular}{|c|c|c|c|c|c|c|}
\hline Recover & $120 \%$ & 97.2 & 97.5 & 106.9 & 99.1 & 97.9 \\
$\mathrm{y}(\%)$ & & & & & & \\
\hline Precisio & Relative & 1.5 & 1.4 & 1.93 & 1.84 & 1.9 \\
$\mathrm{n}$ & Standard & & & & & \\
& $\begin{array}{c}\text { Deviation } \\
\end{array}$ & & & & & \\
\hline
\end{tabular}


Figure 1. Analytes.

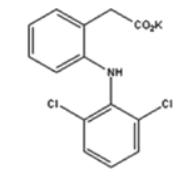

diclofenac potassium

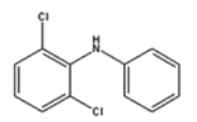

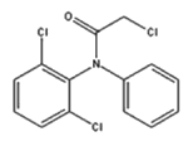

N-chloroacetyl-N-phenyl-2.6- 1-(2.6-dichlorophenyl)-2dichloroaniline indolinone (impurity 1)

(impurity 2)

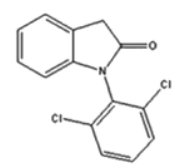

N-phenyl-2.6-dichloroaniline (impurity 3)

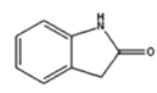

$$
\begin{aligned}
& \text { 2-indolinone } \\
& \text { (impurity 4) }
\end{aligned}
$$


Figure 2. Contour plots for the (A) retention factor for N-phenyl-2, 6-dichloranilin obtained by plotting methanol concentration in the mobile phase as a function potassium hydrogen phosphate concentration at $\mathrm{pH} 3.0$ and (B) selectivity factor for diclofenac potassium and N-phenyl-2, 6dichloranilin obtained by plotting methanol concentration in the mobile phase as a function of potassium hydrogen phosphate concentration at $\mathrm{pH}$ 3.0.
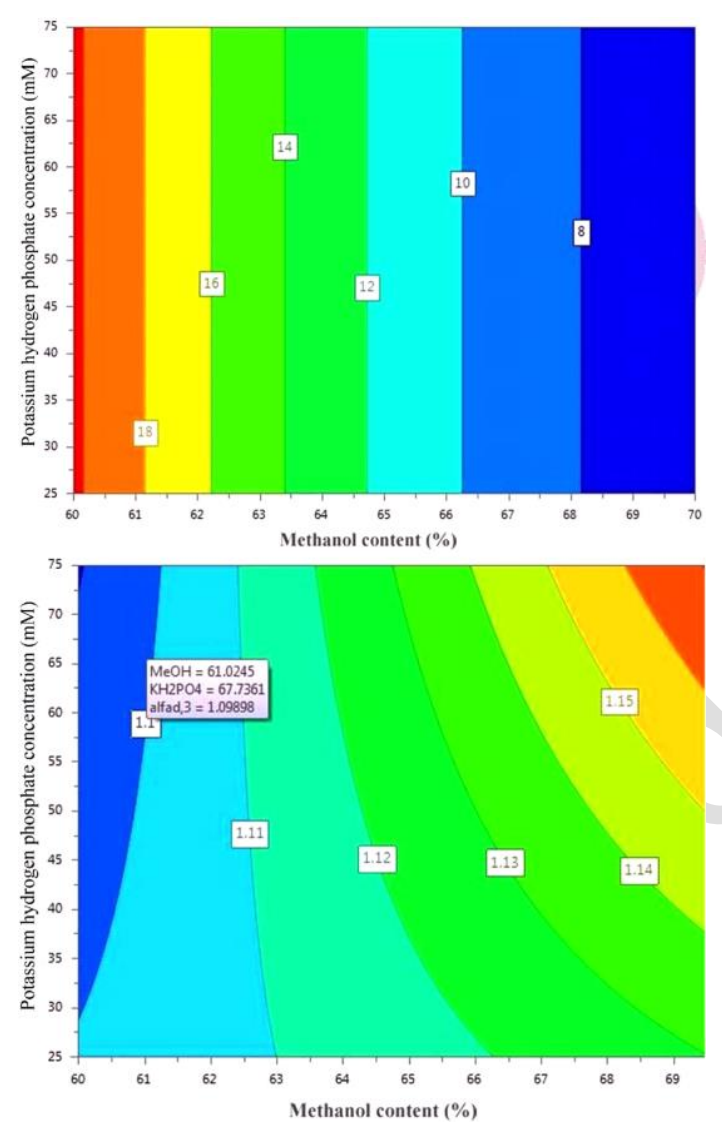
Figure 3. Sweet spot plots obtained by plotting methanol concentration in the mobile phase as a function of potassium hydrogen phosphate concentration in the aqueous phase at $\mathrm{pH} 3.0$ defined by the selectivity factor for diclofenac potassium and N-phenyl-2, 6-dichloranilin $>1.12$ and the retention factor for $\mathrm{N}$-phenyl-2, 6-dichloranilin $<10$. Regions where only one criterion was met are blue; regions where both criteria were met are green.

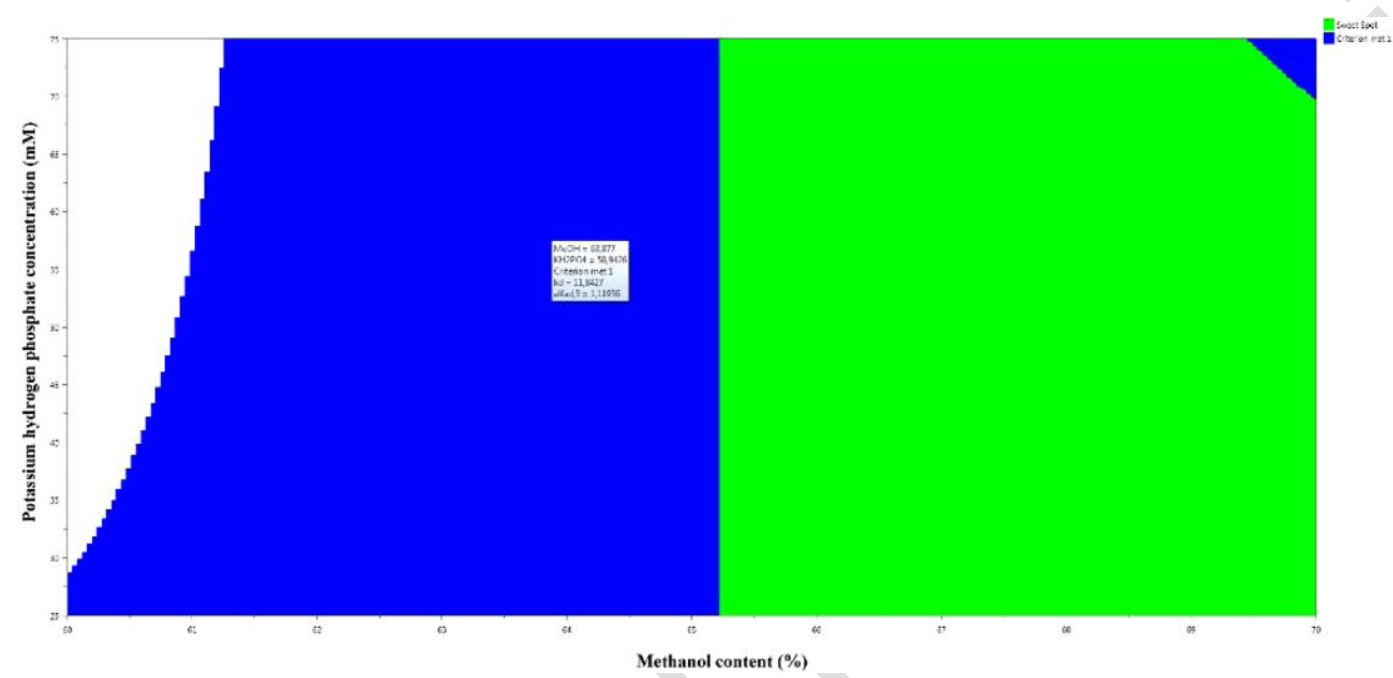


Figure 4. Design space for the separation of diclofenac potassium and its impurities for methanol and potassium hydrogen phosphate concentrations in the aqueous phase at $\mathrm{pH}$ 3.0.

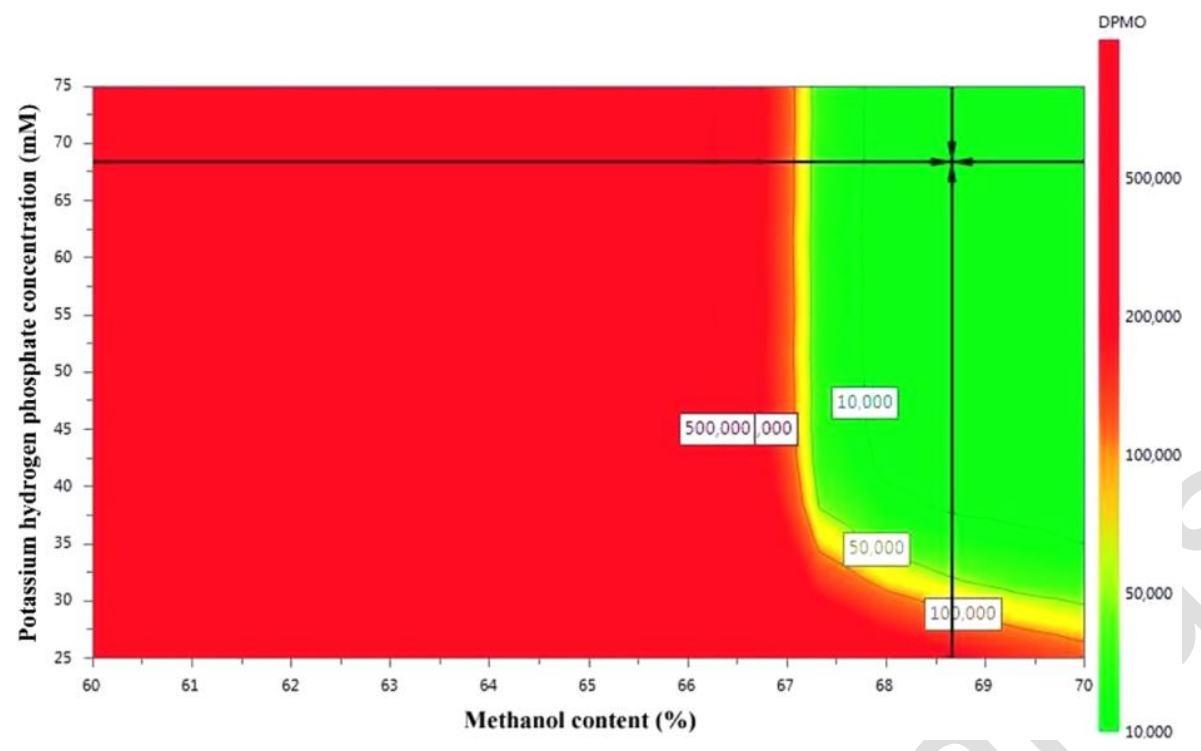


Figure 5. Chromatogram of diclofenac potassium and its impurities under the optimal conditions: (1) 2-indolinon (1-H-indol-2-ol), (2) 1-(2, 6-dichlophenyl)-2-indolinon, (3) Nchloroacetyl-N-phenyl-2, 6-dichloroanilin, (4) diclofenac potassium, and (5) N-phenyl-2, 6dichloranilin.

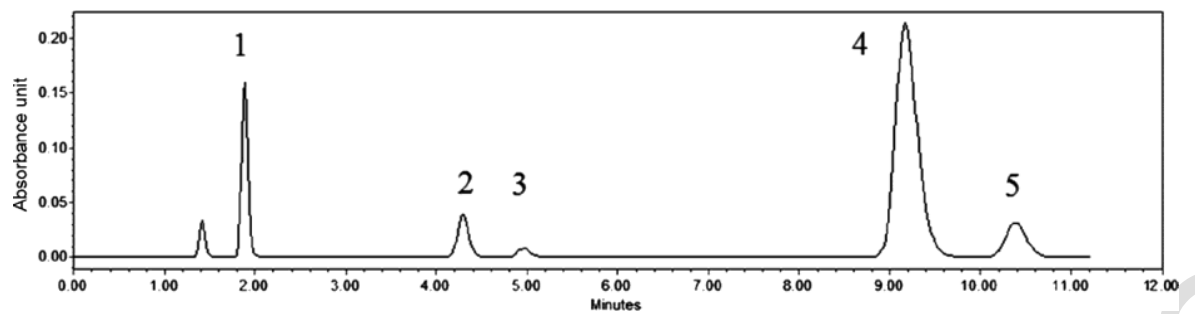

